\title{
Assessing Food Poverty, Vulnerability and Food Consumption Inequality in the Context of COVID-19: A Case of Bangladesh
}

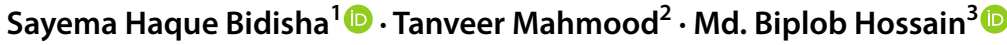

Accepted: 15 December 2020 / Published online: 4 January 2021

(c) The Author(s), under exclusive licence to Springer Nature B.V. part of Springer Nature 2021

\begin{abstract}
There is no denying the fact that, for a developing country like Bangladesh, the economic consequences of lockdown for containing COVID-19 pandemic can be far reaching affecting livelihoods of millions of households. Given that the share of food consumption expenditure to total expenditure is higher in the lower income groups of Bangladesh, this shock is expected to directly affect affordability of consumption of basic food items of these households. Using nationally representative household survey data of Bangladesh, and while following the Feasible Generalized Least Square method, this paper attempts to examine food poverty, food consumption inequality along with vulnerability to food poverty of households and explores the importance of different socio-demographic and environmental factors in this connection. Our estimation reflects that, greater percentage of households with young children or with elderly people are found to suffer high food vulnerability. In addition, households in environmentally endangered regions e.g. drought prone areas or river erosion affected places are more food vulnerable than those in other parts of the country. Certain occupation groups e.g. day labourer and self-employed are found to be highly vulnerable to food poverty while according to our decomposition analysis of food consumption inequality, area of residence (urban vs. rural) is expected to cause sizable inequality in food consumption. This study can therefore, help in identifying food vulnerable households for government's social protection programs and COVID-19 incentive packages, and thereby can contribute towards designing effective poverty reduction strategies.
\end{abstract}

Keywords Food poverty · Food vulnerability · Food consumption inequality. COVID-19 . Bangladesh

Sayema Haque Bidisha

sayemabidisha@gmail.com

1 Department of Economics, University of Dhaka, Dhaka 1000, Bangladesh

2 Bangladesh Institute of Development Studies (BIDS), E-17 Agargaon, Sher-e-Bangla Nagar,

Dhaka 1207, Bangladesh

3 Independent Researcher, Dhaka 1000, Bangladesh 


\section{Introduction}

There is no denying the fact that the economic consequences of lockdown for containing COVID-19 pandemic can be far reaching. It may exacerbate the socio-economic condition of those who are currently poor or are vulnerable to become poor. According to a recent study, four out of five of the 'new poor' created by this pandemic will be living in SubSaharan Africa and South Asia (Sumner et al. 2020). With $85 \%$ of its work force in informal employment, this has resulted in shrinking in production and loss in income of a large number of people of Bangladesh.

In the last decade or so, Bangladesh has attained more than $6 \%$ of GDP growth with impressive progresses in a number of socio-economic indicators e.g. life expectancy, school enrolment etc. In terms of reduction of poverty, the country has fared quite well too, with the headcount poverty rate declined from $31.5 \%$ in 2010 to $24.3 \%$ in 2016 (BBS 2019). However, concern still remains on the distributional aspects of growth as well as on the persistence of poverty. In this context, a number of economic as well as environmental factors have contributed towards vulnerability of people at lower end of income distribution. The consequence is expected to be even stronger on food poverty in particular, as households of lower income strata spend more on food than on non-food (BBS 2019).

Food poverty can be defined as a situation when a household lacks resources to afford a nutritionally sufficient diet on a day to day basis. As argued by Ozughalu (2016), in poorer countries, households spend much larger amount on food items than on non-food items and therefore poverty is often considered to be synonymous to hunger, which makes it more appropriate to look at food poverty of households instead of poverty per se. Vulnerability to food poverty, on the other hand, is a dynamic concept which can be viewed as the probability that the food consumption of a household will lie below the predetermined food poverty line in near future, induced by shocks, risks, uncertainty and many other unforeseen events (Chaudhuri 2003). In this paper, against the backdrop of COVID-19, with the help of a nationally representative household survey of Bangladesh, we attempted to provide a detailed analysis of food poverty, vulnerability to food poverty and inequality in food consumption. In this regard, we applied standard Foster-Greer-Thorbecke indices (FGT) (Foster et al. 1984) of food poverty and feasible generalized least square (FGLS) based estimation of food vulnerability along with an application of Blinder-Oaxaca decomposition analysis to examine food consumption inequality (Oaxaca 1973; Blinder 1973). Due to differences in food consumption across different groups of households based on household characteristics and area of residence, we estimated food poverty and food vulnerability across different household groups. Besides, due to diversity in food consumption across areas of residence e.g. rural and urban areas, we attempted to examine food consumption inequality as well.

This analysis is of particular importance for a number of reasons. Firstly, though a significant number of studies explored poverty, to our knowledge, no study has conducted a detailed analysis of food poverty, vulnerability to food poverty and inequality of food consumption expenditure for Bangladesh. Secondly, with consumption expenditure consists of food and non-food component with the former constituting a substantial part of the lower income households of Bangladesh, disaggregating the total consumption expenditure and a closer inspection of the food component in particular, is rather necessary to confirm whether there exists any disparity between the two. From a policy point of view, a disaggregated analysis can offer better insights in understanding the poverty profile of households. Thirdly, in the absence of any comprehensive study of household poverty against the 
backdrop of COVID-19 in Bangladesh, while applying the method of food vulnerability with the most recent nationally representative survey, this research is expected to provide a guideline for understanding the impact of such shock on household's food consumption behavior. Fourthly, although it is natural to expect that variability of food consumption is relatively lower across different households, greater variability in food consumption may still be present among broad household categories e.g. rural and urban households. Understanding such consumption variability (if any) may have crucial policy implications in terms of poverty alleviation strategies. In addition, given the differences in food poverty and food vulnerability across different households based on household characteristics as well as area of residence, focusing particularly on environmentally vulnerable regions, this analysis offers important insights for designing specific poverty reduction strategies for different groups of households.

The rest of the study is organized as follows: Section two discusses theoretical and econometric issues regarding the measurement of food poverty, vulnerability and inequality in food consumption based on empirical literature. Section three provides a brief description of the data used in the analysis and describes the methods employed in the measurement of poverty, vulnerability and inequality. Key findings of the study are organized in several subsections, particularly in section four and five. Section six concludes the study with a summary while providing some policy recommendations.

\section{Empirics of Food Poverty, Vulnerability and Inequality}

The first step to estimate food poverty requires a proper estimation of food poverty line. To keep consistency with national estimates, the official food poverty lines provided by the BBS in HIES 2016 should be used in this regard. As outlined in the official report of the survey, first, a basic consumption bundle was selected, where the bundle includes eleven items i.e. coarse rice, pulses, wheat, milk, meat, oil, and fish, potatoes, other vegetables, sugar and fruits (BBS 2019). The list has been formulated while following Ravallion and Sen (1996) and Alamgir (1974). This bundle meets the minimum daily nutritional requirements of 2122 kilo calorie per person. Cost of acquiring the basket was then estimated and for this the median of unit values (price per unit) for each of the items was calculated separately for each stratum. In the calculation, 2nd-6th deciles of the per capita consumption group were used as the reference group. Finally, the food poverty line was obtained as the product of the estimated prices and quantities of food consumption bundle. The poverty lines calculated in this manner are distinct for each of the stratum.

Exposure of households to different kind of idiosyncratic and covariate shocks in developing countries like Bangladesh is a common phenomenon (Osmani and Ahmad 2013) and a household may be exposed to both kind of shocks at the same time. ${ }^{1}$ The recent pandemic i.e. COVID-19 has a strong bearing here: although being primarily a covariate shock in nature, the effects of this pandemic are channeled to the households by increasing its exposure to idiosyncratic shocks (illness, death, unemployment etc.) as well. One might argue that households develop their own risk coping mechanism against shocks and try to smooth their consumption against income fluctuations. Nevertheless, households still may face

\footnotetext{
1 While covariate shocks (natural disasters, pest and disease outbreak, pandemics, drought, climate change, land degradation etc.) adversely affect a large portion of the population in a geographical area, idiosyncratic (for example, illness, loss of job, death etc.) shocks affect households within a community.
} 
high consumption variability (Townsend 1994; Udry 1995) which raises question against ex post poverty measure to be taken for granted as a serious guideline for policy purpose. Traditional poverty measurement such as FGT measure (Foster et al. 1984), which is widely exercised in many countries by the policy makers, does not take the dynamic aspects of poverty into account. Thus, it becomes necessary to measure vulnerability to poverty, which captures the dynamic aspect of consumption and is an ex ante measure of poverty.

Hoddinott and Quisumbing (2003) summarizes vulnerability to poverty analyses into three major approaches. Firstly, vulnerability as expected low utility (VEU), in which vulnerability is defined as the difference between the utility level obtained from a thresholdlevel certainty-equivalent consumption, and to the expected utility level of consumption expenditure for individuals (Ligon and Schechter 2003; Elbers and Gunning 2003). Secondly, vulnerability is defined as uninsured exposure to risk, which is basically an ex post assessment of the extent to which a negative shock results in an observed welfare loss. Thirdly, vulnerability as expected poverty (VEP) defines vulnerability as the probability that a household will fall into poverty in future time period. The third method was applied by Chaudhuri, Jalan and Suryahadi (2002) and Christiaensen and Subbarao (2001) etc. among others to examine vulnerability. Fujii (2016) on the other hand, described an axiomatic approach, under which, as proposed by Calvo and Dercon (2005), a set of axioms were defined that listed necessary properties that a standard measure of vulnerability would satisfy. Vulnerability, as defined by them, is based on these axioms. ${ }^{2}$

However, unavailability of panel data has made it quite difficult to explore the dynamic nature of poverty, especially in the developing countries. However, Chaudhuri (2003) has offered a methodology which makes it possible to estimate vulnerability to poverty with cross-sectional data. This approach relies on rather a strong assumption that the cross-sectional variance can at least partially explain the inter-temporal variation in consumption. Azam and Imai (2009) pointed out that such an inter-temporal variance can be explained by cross-sectional variance in the presence of covariate or community specific shocks and idiosyncratic shocks provided the cross-sectional data is based on a large sample with some households facing negative shocks. ${ }^{3}$ Another important aspect to be taken into consideration is we need to allow for heteroskedasticity in the consumption process to interpret variance of the disturbance term as inter-temporal variation.

Although a comprehensive understanding of food inequality would require capturing multidimensional distribution of welfare, nevertheless, a simple measure like that of Gini index, or related graphical tools (Lorenz curve, Concentration curve etc.) could be employed to get a basic understanding. In the context of developing countries like Bangladesh, amidst a pandemic, it is also useful to examine the existence of potential disparity among urban and rural households. However, if there is any difference in rural and urban food consumption level, the Gini coefficient sometimes may fail to capture the effect. In that case, Blinder-Oaxaca decomposition (Oaxaca 1973; Blinder 1973) method allows one to explore such expenditure gaps.

Much of the empirical work on food poverty has however dealt with the static aspect of food consumption. Crawford and Thorbecke (1980) explored incidence of food poverty among the smallholder households of the regions of Kenya and found that almost

\footnotetext{
${ }^{2}$ Hoddinott and Quisumbing (2003) and Fujii (2016) offer introduction and summary for a review of the concepts and measurements of vulnerability.

3 The econometric issues are discussed in detail in Chaudhuri (2003).
} 
one-fourth of the households' food intake was below the recommended daily allowance. Greer and Thorbecke (1986a, b) through a cost of calories function, devised a new way of measuring food poverty line which accounted for regional food preferences and prices. Greer and Thorbecke (1986a, b) used this regression based food poverty line estimation to explore the incidence of food poverty among the households of Kenya and compared their results with the other two methods. Greer and Thorbecke (1986a, b) further explored this novel method by adopting a detailed decomposition of the estimated food poverty of Kenyan households. Kyereme and Thorbecke (1987) used the Engel semi-log regression model to derive a monetary food poverty line and estimated food poverty in Ghana. While including socio-economic and region specific variables in their model, they found higher prevalence of food poverty in rural areas and also among larger households and female headed households. Using Ghana Household Budget Survey, Kyereme and Thorbecke (1991) devised a multivariate regression model based on household production theory and identified the determinants of food poverty and net contribution of children to household food availability. Their regression results suggested that income, fertility, sex of the household, age of the household, education, and maturity indices could significantly explain calorie gaps among households. Nyariki and Wiggins (1997) explored food insecurity and poverty using data collected from two rural regions of Kenya and used the cost of basic needs $(\mathrm{CBN})$ approach to estimate the food poverty line.

In the context of vulnerability to food poverty, a meagre number of research has been done. Ozughalu and Ogwumike (2013) applied a three step feasible general least square (3FGLS) procedure proposed by Chaudhuri (2003), to estimate vulnerability to food poverty. One interesting finding of this study, which used nigeria living standard survey (NLSS-2004) data, is that vulnerability to food poverty is higher in urban areas than in rural areas. Ozughalu (2016) applied a least-cost technique of food-energy intake approach, to estimate region specific food poverty line, proposed by Greer and Thorbecke (1986a, b) and applied a 3FGLS method to estimate to vulnerability to food poverty. This study found that the food poor group is more vulnerable than the non-food poor group. Zereyesus, Emabaye and Tsiboe (2017) adopted the FLGS method proposed by Chaudhuri, Jalan and Suryahadi (2002), to estimate vulnerability to food poverty and explored whether household member's participation in non-farm work had an impact on the vulnerability to food poverty status of a household. The study revealed that, participation in non-farm work significantly increased expected future consumption and thereby decreased the likelihood to become vulnerable to food poverty. Using geo-referencing and mapping techniques, Olayide and Alabi (2018) assessed vulnerability of climate change in an agrarian economy and explored the relationship between rain fall variability and food poverty. This study suggested for transforming the agriculture of Nigeria along the dimensions of vulnerability.

In connection with food consumption, most of the studies in Bangladesh are rather concerned about food security, a somewhat related, but distinct concept (Faridi and Wadood 2010; Rabbani 2014; Bidisha et al. 2017). On the other hand, literature with special attention to food poverty is rather scanty (Khandker 2012). There are a number of studies which have conducted vulnerability to poverty analysis for Bangladesh. Azam and Imai (2009) while using household income and expenditure survey (HIES)-2005 applied the 3FGLS procedure proposed by Chaudhuri, Jalan and Suryahadi (2002); Chaudhuri (2003) and Suryahadi and Sumarto (2003). Azam and Imai (2012) while using the HIES 2005, estimated the vulnerability to poverty and decomposed it while using a two level random intercept model. This study found that, idiosyncratic shocks have higher impact on relatively well-off household's vulnerability and covariate shocks have higher impact on poorer and less educated household's vulnerability. Borkotoky 
and Unisa (2018) while using Theil Decomposition and Gini Decomposition technique, assessed the level of inequality in food expenditure in India. This study further utilized Oaxaca Blinder Decomposition (Oaxaca 1973; Blinder 1973) method, to assess the factors contributing to inequality in food consumption and found that occupation type and household size significantly contributed towards this.

A number of studies were conducted to measure the impact of the COVID-19 on poverty, inequality and food security. Based on a telephone survey during the month of April, 2020 on 5471 households of urban slum areas of 9 districts and rural areas of 64 districts of Bangladesh, Rahman et al. (2020) explored the impact of COVID-19 on livelihoods of households and the coping mechanism adopted by them. The paper found that due to COVID-19 crisis urban slum households experienced a decrease in food expenditure by $28 \%$, whereas for the rural households it was $22 \%$. In addition, the research revealed a significant drop in the percentage of households who could not afford a 3 meals per day diet- about $24 \%$ households of urban slum areas and $14 \%$ rural households could not afford a 3 meals per day diet. In order to explore the impact of general holidays of the Government of Bangladesh to contain the spread of COVID19 virus on household's socio-economic conditions, food insecurity, mental health and intimate partner violence, Hamadani et al. (2020) surveyed mothers from 2417 households of Rupganj Upazila of Narayanganj District of Bangladesh where they found that during the general holiday, the number of households experiencing food insecurity increased by $51.7 \%$. They found that the proportion of moderately food insecure households increased from $5.6 \%$ (pre-lockdown condition) to $36.5 \%$ and for the severely food insecure households, the change was from 2.6 to $15.3 \%$. In another study, Mottaleb et al. (2020) while using Household Income and Expenditure Survey of Bangladesh estimated daily per capita expenditure for both farm and non-farm households and then assuming 10, 20 and $30 \%$ of the daily earnings of the households in comparison to pre-covid time, they found that to ensure minimum food security of households, on an average it was necessary to provide BDT 51-104 or around one dollar daily as a minimum compensation.

\section{Data and Methodology}

\subsection{Data}

The study has utilized household income expenditure survey (HIES) 2016 which is a cross-sectional survey data used for national poverty estimates. It is the largest nationally representative dataset of Bangladesh which contains detailed information on household income, expenditure, education, health and sanitation, access to basic utilities, households assets, employment status, shocks and coping mechanisms, participation in social safety nets along with other demographic characteristics of households and its members. The HIES 2016 was collected while using two stage stratified cluster sampling design. With eight administrative divisions in the country, primary sampling units (PSUs) were implicitly sub-stratified under 64 districts. The PSUs were selected using the framework based on Census of Population and Housing 2011. The survey was conducted for 46,080 households drawn randomly from 2304 PSUs and the data were collected for a number of $1,86,046$ individuals. 


\subsection{Estimates of Poverty and Inequality}

We know that, Gini Coefficient is considered as a prominent index to estimate the degree of deviation of a distribution (here, food consumption) of a group from the perfectly equal distribution. For the calculation of inequality we have used this index.

$$
\text { Gini }=\frac{2 \operatorname{Cov}(X, F)}{M}
$$

Here, $\mathrm{X}$ is the total food expenditure, $\mathrm{F}$ is the cumulative distribution of $\mathrm{X}$ and $\mathrm{M}$ is the mean of $X$.

For the calculation of food poverty, food poverty gap (FPG), Square of food poverty gap (SFPG) we have used the estimates of FGT (Foster et al. 1984) index.

$$
F G T=1 / n \sum_{j=1}^{q}\left[\frac{(z-y j)}{z}\right]^{\alpha}
$$

where $\mathrm{n}=$ total number of population, $\mathrm{q}=$ total number of poor, $\mathrm{z}=$ Food poverty line, $\mathrm{y}$ $\mathrm{j}=$ Per capita consumption.

$\alpha \geq 0$, and for $\alpha=0,1,2$ we get head count ratio of food poverty, FPG, SFPG respectively. Head count ratio of poverty identifies the proportion of food poor in the population. Food poverty gap shows both the food poverty incidence and intensity of food poverty. Squared food poverty gap measures the severity of food poverty.

\subsection{Vulnerability to Food Poverty Estimation}

Vulnerability to food poverty can be viewed as an ex-ante expectation of food poverty which is, in other words, the probability that the food consumption of a household will lie below the predetermined food poverty line in near future. In the absence of nationally representative panel data set, as an alternative, in this analysis, a methodology applied by Chaudhuri (2003) was followed.

In this context, firstly we can specify the consumption of household $\mathrm{h}$ as follows:

$$
\operatorname{lnc} c_{h}=X_{h} \beta+\varepsilon_{h}
$$

$c_{h}=$ Per capita consumption expenditure on food items. $X_{h}=$ Bundle of observable household characteristics. $\beta=$ Vector of Parameters. $\varepsilon_{h}=$ mean-zero disturbance term that captures idiosyncratic factors (shocks).

Assuming the variance of $\varepsilon_{h}$ is given by:

$$
\sigma_{\varepsilon, h}^{2}=X_{h} \theta
$$

Estimating Eq. (3) using OLS

$$
\varepsilon_{O L S, h}^{2}=X_{h} \theta+\eta_{h}
$$

The predictions from Eq. (5) are used to transform the equation as follows:

$$
\frac{\varepsilon_{O L S, h}^{2}}{X_{h} \hat{\theta}_{O L S}}=\left(\frac{X_{h}}{X_{h} \hat{\theta}_{O L S}}\right) \theta+\frac{\eta_{h}}{X_{h} \hat{\theta}_{O L S}}
$$


This transformed equation is estimated using OLS to obtain an asymptotically efficient FGLS estimate, $\hat{\theta}_{F G L S}$. And from Eq. (4) we know $X_{h} \widehat{\theta}_{F G L S}$ is a consistent estimate of $\sigma_{\varepsilon, h}^{2}$ (variance of the idiosyncratic component of household consumption of food items).

The estimates:

$$
\hat{\sigma}_{\varepsilon, h}=\sqrt{X_{h} \hat{\theta}_{F G L S}}
$$

are used in the transformed equation as follows:

$$
\frac{\ln c_{h}}{\hat{\sigma}_{\varepsilon, h}}=\left(\frac{X_{h}}{\hat{\sigma}_{\varepsilon, h}}\right) \beta+\frac{\varepsilon_{h}}{\hat{\sigma}_{\varepsilon, h}}
$$

We can get the standard error of the estimated coefficient, $\widehat{\beta}_{F G L S}$ by dividing the reported standard error by the standard error of the regression.

Using $\hat{\beta}_{F G L S}$ and $\hat{\theta}_{F G L S}$ we can estimate the mean

$$
\hat{E}\left[\ln c_{h} \mid X_{h} \hat{\beta}\right]=X_{h}
$$

and the variance of the log of food-consumption

$$
\hat{V}\left[\ln c_{h} \mid X_{h}\right]=\sigma_{\varepsilon, h}^{2}=X_{h} \hat{\theta}
$$

Assuming that food consumption is log normally distributed we can be able to use these estimates to form an estimate of probability that a household the $X_{h}$ characteristics will be food poor. Let us denote the cumulative density of the standard normal distribution as $\varphi()$. Now the estimated probability will look like:

$$
\hat{V}_{h}=\hat{\operatorname{Pr}}\left(\ln c_{h}<\ln z \mid X_{h}\right)=\varphi\left(\frac{\ln z-X_{h} \hat{\beta}}{\sqrt{X_{h} \hat{\theta}}}\right)
$$

Here, $\varphi()=$. Cumulative density of the standard normal distribution functoon. $z=$ poverty line.

Households (or individuals dwelling there) with probability greater than or equal to 0.50 can be considered as highly vulnerable to food poverty.

\subsection{Vulnerability and Time Horizons}

Chaudhuri (2003) has considered the time horizon of vulnerability to poverty in two possible cases. One is a time horizon of 1 year, which portrays the likelihood of falling into poverty in the short run and the other one is a time horizon of 3 years. The later one allows us to understand the likelihood of all the households to fall into poverty at least once in the following 3 years.

Now if we have a vulnerability threshold $V_{n}=0.5$ which indicates the probability of falling into poverty at least once in the upcoming $\mathrm{n}$ number of years, we can get a general equation to estimate vulnerability at various time horizons

$$
V^{*}=1-\sqrt[n]{1-V_{n}}
$$


While using Eq. (12) we can get vulnerability threshold of 1, 2 and 3 years as $0.5,0.292$ and 0.206 respectively.

\section{Categories of Poverty and Vulnerability ${ }^{4}$}

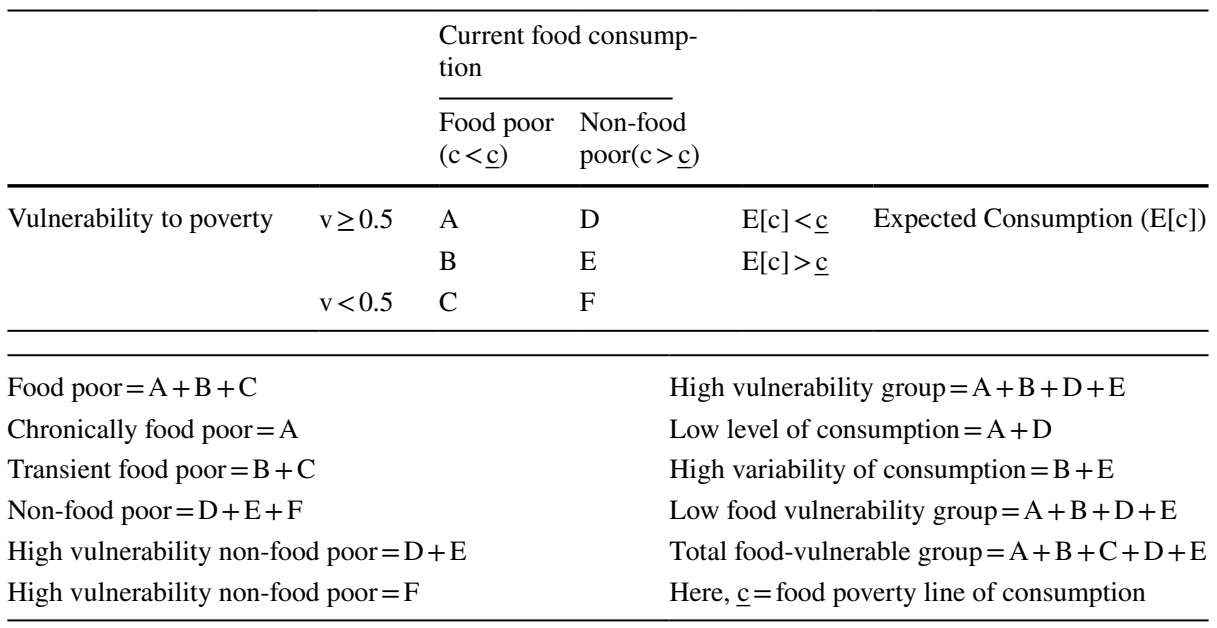

\subsection{Oaxaca Blinder Decomposition}

In the context of poverty and vulnerability analysis, it is often interesting to explore whether living in rural or urban areas makes a sizeable difference in food consumption expenditure. In other words, we want to know whether there is any difference or inequality in food consumption expenditure among rural and urban households. Blinder-Oaxaca decomposition (Blinder 1973; Oaxaca 1973) helps us to answer such questions. Let us consider a linear model as shown in Eq. (13):

$$
\ln C_{j}=X_{j} \beta+\varepsilon_{j}, E\left[\varepsilon_{j}\right]=0 \text { and } j \in(\text { Urban, } R=\text { Rural })
$$

where, $C_{j}$ is the per-capita food expenditure, $X_{j}$ is a vector containing variables predicting the per-capita food expenditure and a constant, $\beta$ is a vector of coefficients and the intercept and $\varepsilon_{j}$ is the error part.

Now the mean difference of natural logarithm of per capita food expenditure can be written as

$$
D=E\left(C_{U}\right)-E\left(C_{R}\right)=E\left(X_{U}\right) \beta_{U}-E\left(X_{R}\right) \beta_{R}
$$

Following Winsborough and Dickinson (1971), Jones and Kelley (1984) and Daymont and Andrisani (1984), Eq. (14) can be rearranged as follows:

$$
D=\left\{E\left(X_{U}\right)-E\left(X_{R}\right)\right\} \beta_{R}+E\left(X_{R}\right)\left(\beta_{U}-\beta_{R}\right)+\left\{E\left(X_{U}\right)-E\left(X_{R}\right)\right\}\left(\beta_{U}-\beta_{R}\right)
$$

\footnotetext{
${ }^{4}$ Suryahadi and Sumarto (2003) offer a detailed methodology for this estimation.
} 
From equation we can see that the natural logarithm of difference is divided into three components.

$$
D=E+C+I
$$

The first component is called the Endowment effect which accounts for the part gap due to group differences in the regressors, $E=\left\{E\left(X_{U}\right)-E\left(X_{R}\right)\right\} \beta_{R}$

The second component is called Coefficient effect. It measures the effects of differences in the coefficients.

$$
C=E\left(X_{R}\right)\left(\beta_{U}-\beta_{R}\right)
$$

And the third component is also known as interaction effect. It shows the effects of simultaneous differences of endowments and coefficients. $I=\left(\beta_{U}-\beta_{R}\right)$

The decomposition portrayed in the equations are constructed from the rural group's point of view. Expected change in rural group's mean per capita food expenditure is measured by the 'endowment effects' if rural group had urban group's predictor levels. Similarly the expected change in rural group's mean per capita food is measured by the 'coefficient effect" if rural group had urban group's coefficients.

\section{Descriptive Findings}

\subsection{Description of Key Socio-Economic Variables}

As shown in Table 1, most of the households are headed by middle aged men with the average age of household head being 44.77 years with only $12.63 \%$ households headed by females. On an average, there are four to five members in each household with both rural and urban areas having almost similar family sizes. However, in terms of educational attainment, urban households on an average, are found to have higher mean years of education with the national average being 4.22 years. We have observed a significant proportion of household heads working as day labourer $(41.37 \%)$ with another sizable portion (38.35\%) working as self-employed and around $36 \%$ involved in agriculture. As expected, we have also found rural heads engaged in overwhelming proportion in agriculture whereas the urban dwellers are mostly found to be either day labourer $(31.63 \%)$ or are involved in self-employment activities (31.96\%). In our sample, around $16.41 \%$ households receive remittance from migrant members of household. In terms of access to basic utility services, although we have found $74 \%$ households having access to electricity and $43.71 \%$ having safe water, only $22.46 \%$ are found to use sanitary latrine at homes. Though housing condition are found to be poor for $23.35 \%$ households, as high as $78.46 \%$ household heads use mobile phone. One alarming feature that we observe in our sample is the presence of chronically ill member and as high as $30.59 \%$ households reported to have at least one member with chronic illness. Besides, $14.66 \%$ households reported to have experienced any kind of shock in last 1 year. 
Table 1 Summary Statistics for households. Source: Household Income Expenditure Survey-2016, Own calculations.

\begin{tabular}{lccr}
\hline & National & Rural & Urban \\
\hline Household characteristics & & & \\
Per capita food expenditure (mean) & 1744.5 & 1653.9 & 1956.8 \\
Age of HH head (mean years) & 44.77 & 45.12 & 43.96 \\
HH size (mean) & 4.64 & 4.67 & 4.57 \\
Dependency ratio & 0.37 & 0.38 & 0.34 \\
Female headed HH (\%) & 12.63 & 12.44 & 13.06 \\
Educational attainment of the HH head (mean years) & 4.22 & 3.56 & 5.72 \\
HH works in agriculture (\%) & 36.13 & 46.27 & 12.93 \\
HH head works as a day labourer (\%) & 41.37 & 45.37 & 31.63 \\
HH head is self-employed (\%) & 38.35 & 40.97 & 31.96 \\
HH is remittance recipient (\%) & 16.41 & 17.27 & 14.45 \\
HH has at least one member with chronic illness (\%) & 30.59 & 31 & 29.63 \\
Total Operating land (mean acres) & 0.73 & 0.89 & 0.36 \\
HH has access to safe water (\%) & 43.71 & 38.75 & 55.33 \\
HH uses sanitary latrine (\%) & 22.46 & 18.83 & 30.97 \\
HH with poor housing condition (\%) & 23.35 & 27.92 & 12.67 \\
HH has access to electricity (\%) & 73.00 & 64.93 & 91.88 \\
HH has access to internet (\%) & 7.85 & 5.51 & 13.32 \\
HH head uses mobile phone (\%) & 78.46 & 75.87 & 84.40 \\
HH has experienced a shock in last 12 months (\%) & 14.66 & 17.24 & 8.62 \\
\hline
\end{tabular}

\section{Model Estimation Results}

\subsection{Household Food Poverty}

Based on standard calorie requirement, the national food poverty threshold is defined at 2122 kilo calorie daily requirement per capita and the relevant expenditure calculated for each of the broad geographical areas can be considered as the corresponding food poverty line expenditure. Based on the methodology as in Sect. 3, as high as $35.49 \%$ households are unable to meet the expenditure threshold of minimum calorie requirement as defined by HIES 2016. Besides, $11.07 \%$ of households are chronically food poor-according to our definition, these households will not be able to upgrade themselves from food poverty in near future and/or these households will remain poor regardless of any shock or not (Table 2). The remaining households (24.42\%) are transient food poor- some of these households might be able to graduate from food poverty in the next period. Food poverty gap and squared food poverty gap have been estimated as 8.99 and 3.0 respectively. (BBS 2019).

\subsection{Vulnerability to Food Poverty}

The regression results carried out by Ordinary Least Squares technique for Eq. (3), where log of per capita food consumption is estimated by household idiosyncratic characteristics 
Table 2 Category-wise and time horizon-wise poverty and vulnerability. Source: Household Income Expenditure Survey-2016, Own calculations

\begin{tabular}{llcr}
\hline & National (\%) & Rural (\%) & Urban (\%) \\
\hline Categories of poverty & & & 7.51 \\
Chronically food poor(CP) & 11.07 & 12.62 & 21.66 \\
Transient food poor(TP) & 24.42 & 25.63 & 29.17 \\
Total food poor (TFP-HH wise) & 35.49 & 38.25 & 7.11 \\
Food poverty gap (FPG) & 8.99 & 9.8 & 2.3 \\
Squared food poverty gap (SFPG) & 3 & 3.3 & 7.63 \\
Categories of Vulnerability & & & 19.16 \\
Highly vulnerable food non-poor (HVNFP) & 9.03 & 9.64 & 36.8 \\
High vulnerability to food poverty (HVP) & 24.36 & 26.63 & 47.89 \\
Total vulnerable to poverty (TP) & 44.52 & & 33.68 \\
Time Horizon-wise & & 42.63 & 42.26 \\
Vulnerability to food-poverty in year 2 & 39.91 & 51.44 & \\
Vulnerability to food-poverty in year 3 & 48.65 & & \\
\hline
\end{tabular}

and other determinants, can be found in Table 7 of appendix. Although for brevity, we left the interpretation of the results for the reader, a few words must be said about variable selection and estimation. In the regression model, age of household head, household size and total operating land have been used in the model along with the squared terms to capture their non-linear relationship with log of food consumption, if there is any. However, since linear and quadratic terms are highly correlated, the variables were first centered (by subtracting the mean) before they were squared. Following the suggestion of Azam and Imai (2009), a dummy variable of 'housing condition' of the household has been kept in the model as it might be a regular and major source of shocks for Bangladeshi households. This is because households, particularly those living in rural or coastal areas, even in plain lands, have to spend significant amount of money for reconstruction and repair as they often fall victim to natural calamities like cyclone, tidal surge, river erosion, flood etc. If the condition of roofs and walls of the main room in the household is good i.e. if wall and roof are made of tin (CI sheet)/brick/cement/wood, the housing condition is considered to be good. On the contrary, if the walls and roofs are made of straw/bamboo/polythene/plastic/canvas/mud/unburnt brick, the housing condition is considered to be poor. Dummy of whether household has access to internet, or uses mobile phone, or uses computer are used to capture the effect of information usage. The reasons behind the inclusion of other variables are self-explanatory and with a few exceptions, most of the variables have produced expected coefficient estimates.

As discussed, the main purpose of our analysis is to understand the key characteristics of food vulnerable households and against the backdrop of COVID-19, it is critical to understand about both the food poor households as well as those who have fallen victim of poverty due to shock in employment and earnings. As shown in Table 2, in terms of vulnerability, in addition to the present $35.49 \%$ food poor households, $9.03 \%$ of previously food non poor are found to be food vulnerable (HVNFP). Thus total food vulnerable households are as high as $44.52 \%$-these households can be considered as those who are unlikely to meet the minimum food requirement after COVID-19 like economic shock. In addition, a quarter of households $(24.36 \%)$ are found to be highly food vulnerable- these 


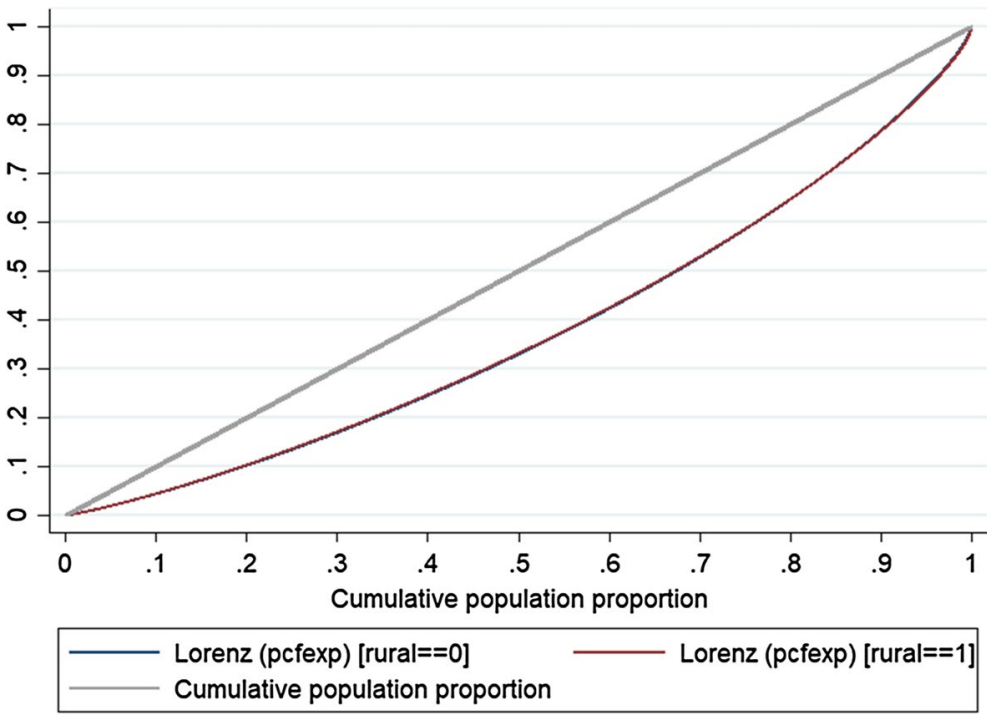

Fig. 1 Lorenz Curve-Rural and Urban Areas. Source: Household Income and Expenditure Survey-2016, Based on own calculations

households are highly likely to fall into food poverty or according to our theoretical model, they would be unable to get out of poverty. One noticeable fact of our calculations of food poverty and food vulnerability is that, the percentage of food poor households is higher than the food vulnerable ones. This finding is opposite to that of Ozughalu (2016) who utilized Nigeria Living Standard Survey (NLSS) of 2004 and calculated vulnerability to poverty for Nigeria.

As discussed in Sect. 3, a dynamic analysis of food poverty is presented in Table 2, which primarily focuses on future probability of households for being food poor. As opposed to $24.36 \%$ highly food vulnerable households in year 1, as discussed in Sect. 3.4, a time horizon of 1 year can be thought of in terms of the likelihood of poverty in the short run, and a time horizon of 3 years can roughly be corresponded to the likelihood of poverty in the medium-term. In this scenario, in year 2 we have found $39.91 \%$ households being food vulnerable whereas $48.65 \%$ households are expected to be food vulnerable in year 3 .

\subsection{Food Poverty and Food Vulnerability Based on Area of Residence}

One important issue that has emerged from Table 2 is the differences in food poverty scenario based on broad area of residence and food poverty is found to be much higher in rural (38.25\%) than in urban areas $(29.17 \%)$. However, the difference is less striking in case of vulnerability to poverty. The food non-poor but food vulnerable (new food poor, HVNFP) in rural areas (9.64\%) is still higher than those in urban areas (7.63\%).

In order to understand food consumption pattern in rural and urban areas, in Fig. 1 of the Appendix, the respective Lorenz curves of food consumption expenditure have been portrayed which reveals that although we observe significant differences in rural and urban food poverty profiles, the distribution of food consumption profile is not that different 
Table 3 Oaxaca Blinder Decomposition of rural-urban food expenditure gap (Overall). Source: Household Income Expenditure Survey-2016, Own calculations

\begin{tabular}{ll}
\hline & Overall decomposition \\
\hline Urban (Group 1) & $7.527 * * *$ \\
& $(0.00386)$ \\
Rural (Group 2) & $7.351 * * *$ \\
& $(0.00252)$ \\
Difference & $0.176 * * *$ \\
& $(0.00461)$ \\
Endowments & $0.0822 * * *$ \\
& $(0.00273)$ \\
Coefficients & $0.0728 * * *$ \\
Interaction & $(0.00561)$ \\
& $0.0207 * * *$ \\
Observations & $(0.00440)$ \\
\hline
\end{tabular}

Robust SE in parentheses

$* p<0.1, * * p<0.05, * * * p<0.01$

across expenditure classes with the inequality in food consumption found to be slightly higher for rural households than their urban counterparts.

\subsection{Decomposition of Food Consumption Based on Area of Residence}

This difference in food consumption found between rural and urban areas as in Sect. 5.3 motivates us to examine the factors behind such differences in greater detail. In particular, through Blinder-Oaxaca decomposition technique, we would like to understand whether living in rural or urban areas contributes to make a sizeable difference in food consumption expenditure. The decomposition results show that, there is sizeable and significant difference or gap in food consumption among rural and urban households in Bangladesh and the differences in endowments account for almost half of the gap in food consumption expenditure (Table 3). Therefore, mean food consumption expenditure of rural households would increase if they had possessed similar characteristics as urban households. On the contrary, if the own characteristics of rural households are kept unchanged, but the parameters of urban households are applied to them, the mean food consumption expenditure would still increase by almost the same amount. However, the interaction term suggests that the simultaneous effect of differences in endowments and coefficients are very small in magnitude. Educational attainment of household head, household size, household head working in agriculture sector, age of household head have sizable contributing factors in explaining differences of endowments and coefficients of food consumption expenditure (see Table 8 of Appendix).

\subsection{Food Poverty and Food Vulnerability by Region}

The differences in food poverty and food vulnerability between rural and urban households indicate the possibility of region wise differences as well. As shown in the upper panel of Table 4, there are interesting differences across administrative divisions and such differences 
Table 4 Region-wise poverty and vulnerability. Source: Household Income Expenditure Survey-2016, Own calculations

\begin{tabular}{lccc}
\hline & Food poor & HVNFP & $\begin{array}{l}\text { High-food } \\
\text { vulnerable }\end{array}$ \\
\hline Administrative division $(\%)$ & & \\
Barisal & 38.09 & 2.69 & 26.82 \\
Chittagong & 30.23 & 1.53 & 17.58 \\
Dhaka & 24.49 & 0.89 & 8.17 \\
Khulna & 34.66 & 2.4 & 21.72 \\
Mymensingh & 41.56 & 3.37 & 34.67 \\
Rajshahi & 43.99 & 3.3 & 35.92 \\
Rangpur & 52.22 & 4.21 & 51.53 \\
Sylhet & 28.43 & 0.85 & 10.2 \\
Environmentally vulnerable regions $($ mean $\%)$ & \\
Coastal area & 36.19 & 1.82 & 18.36 \\
Drought area & 46.63 & 4.22 & 42.39 \\
River erosion area & 48.20 & 1.97 & 27.17 \\
Haor area & 39.93 & 1.41 & 16.94 \\
Char area & 39.09 & 1.92 & 21.64 \\
\hline
\end{tabular}

can be clearly linked to primarily of two different sources: environmental shocks and lack of economic opportunities where the latter can be linked lack of connectivity to bigger cities, low level of industrialization, job creation etc. For example, Rangpur, the northern division of the country with low level of connectivity with the center of the country (capital city Dhaka) and considerable occurrences of seasonal floods and severe drought, is found to host the highest percentage of food poor households (52.22\%) with almost all of these households being highly food vulnerable (51.53\%). In addition, Mymensingh (41.56\%), Rajshahi (43.99\%) and Barisal (38.09\%) divisions are found to have relatively high prevalence of food poor households with high percentages of high food vulnerable households as well. These divisions are often termed as environmentally vulnerable with Mymensingh being a flood prone area, and Barisal being coastal division is prone to salinity and cyclone. On the other hand, Dhaka division which includes the capital and relatively industrialized centrally located districts like Gazipur, Narayanganj comprises of lowest percentages of food poor (24.49\%), followed by the second largest city, the port city of Chittagong (30.23\%). Sylhet division, which is known to be home of many remittance recipient households also have been found to host relatively lesser proportion of food poor and food vulnerable households, on average. But, most of the haors are located in this division. ${ }^{5}$ As seen in Table 4, food poverty is substantially higher i.e. $39.9 \%$ in this subpart of the division. This is rather an indication of potential source of inequality in the division. Another point of fear is: COVID19 is likely to affect the remittance flow, which will appear as a large shock to the remittance recipient households in the division making them vulnerable.

Bangladesh being a tropical country and a delta of the Bay of Bengal is prone to a number of environmental shocks, e.g. cyclone, flood, river erosion, salinity etc. Innumerable rivers and wetlands on one hand and prolonged dry season on the other hand have particularly made

\footnotetext{
${ }^{5}$ Haor areas (Marsh/depressed land) are basically wetlands including rivers, streams, canals, vast areas of cultivated plains which are seasonally flooded, and hundreds of haros and beels varying in size from a few hectares to several thousand hectares. Seasonal floods make the households victim to shocks.
} 
the livelihoods of many of its residents highly challenging and vulnerable. In this context, the lower panel of Table 4 highlights the link between food poverty and food vulnerability and environmentally vulnerable regions. In comparison to national averages, all of the environmentally vulnerable regions e.g. coastal area, drought prone area, ${ }^{6}$ river erosion prone area, Haor area, Char area, ${ }^{7}$ we observe higher degree of food poverty. In addition, drought prone areas are found to have very high prevalence (42.39\%) of households with high food vulnerability. With already high percentages of food poor households, it is not surprising that the percentages of new food poor or non-poor food vulnerable households are not that high.

\subsection{Food Poverty and Vulnerability Explained through Household Head's Socio-Economic Characteristics}

At this stage, we attempt to examine food poverty based on key socio-economic characteristics of households. As can be seen from Table 5, based on land holding profile of households, land ownership appears to safeguard household members from food poverty and as opposed to those who are landless; food poverty is found to be much higher for those with large land holding - the corresponding percentages of food poor households are $38.74 \%$ and $28.98 \%$ respectively. Interestingly, non-poor landless households or those who own small pieces of land have lower incidence of falling into poverty after COVID-19 like shock. Land holding though helps food consumption in current period; it appears to have no positive impact for households' shock coping ability. However Table 5 clearly shows the positive contribution of education level of household head in reducing food poverty with the heads with tertiary education having only $14.94 \%$ incidence of food poverty and less than $1 \%$ of households with heads having tertiary education is found to be highly food vulnerable. Besides, female headed households are found to be more food poor than their male headed counterparts. This finding was similar to that of Oni and Fashogbon (2013) who used Nigeria living standard survey (NLSS) of 2003/04. However a later study which utilized General Household Survey of 2010 to 2013 showed that the scenario has reversed over the year indicating that the prevalence of food poverty was higher in female headed households during that time period (Eigbiremolen and Ogbuabor 2018).

On the other hand, as high as $42.62 \%$ heads without any formal education are found to be food poor with the relevant percentage for high vulnerable food poor is also found to be at a staggering high percentage of $36.27 \%$. For head's broad sector of employment, agricultural households are found to be in much greater degree of food poverty (42.31\%) as well as high likelihood (35.3\%) to turn into food poor after experiencing shock like COVID-19. In terms of broad employment status of household members, there is a clear distinction between food poverty rate of daily labourers and other occupation groups and as high as $46.49 \%$ daily labourers are found to be unable to meet the food expenditure required for minimum calorie consumption with $35.64 \%$ of daily labourers being highly vulnerable to food poverty. On the other extreme, the employers are found to have lesser incidence of food poverty (23.22\%) with $12.8 \%$ having high probability (greater than 0.5 ) to fall below poverty line. It is interesting that, among the non-poor daily labourers or self-employed, more than $11 \%$ are likely to be food poor in case of shock like COVID-19.

\footnotetext{
${ }^{6}$ Districts where most drought prone 30 hotspots (upazilas) are situated have been used in the analysis (Khan and Islam 2013).

7 The char is a tract of land which is surrounded by waters.It is accretion on a river course. They are extremely vulnerable to erosion and flood, and most of them do not persist for stable amount of time making many households exposed to shocks.
} 
Table $5 \mathrm{HH}$ head character-wise poverty and vulnerability. Source: Household Income Expenditure Survey-2016, Own calculations

Food poor HVNFP $\quad$ High-food

HH head Characteristics

Land ownership of $\mathrm{HH}$

38.7

7.74

24.5

Small Land Owner

36.22

8.18

23.35

Medium Land Owner

34.49

11.78

27.79

Large Land owner

28.98

11.69

25.23

Gender of the $\mathrm{HH}$ head

Female Headed

29.21

4.53

12.79

Male Headed

36.49

9.68

26.03

Education of the $\mathrm{HH}$ head

No education

42.62

13.09

36.27

Pre-primary

39.37

10.66

28.2

Primary passed

33.9

7.76

19.66

Lower secondary

27.96

4.36

10.94

SSC passed

23.76

2.29

6.41

HSC passed

21.3

1.2

3.48

Tertiary level

14.94

0.47

0.62

$\mathrm{HH}$ head's sector of working

$\mathrm{HH}$ head works in agriculture sector

42.31

12.93

35.3

$\mathrm{HH}$ head works in non-agriculture sector

Household remittance recipient

Non-Recipient

36.66

9.44

25.65

Recipient

30.4

7.08

17.89

Employment status

Day labourer

46.49

11.67

35.64

Self Employed

32.61

11.05

25.36

Employer

23.22

5.92

12.8

Employee

28.51

4.61

12.45

\subsection{Food Poverty and Food Vulnerability across Different Socio-Demographic Characteristics of Households}

In terms of key demographic features of households, households with more children and elderly people are found to have higher incidence of food poverty along with greater degree of high vulnerability (Table 6). Household demographics appear to be important for not only high food vulnerable households, but also for the new food poor households. As shown in Table 6, greater percentages of non-food poor households with two or more elderly members and/or the non-poor households with three or more number of children are likely to fall below the food poverty line after COVID-19 like shock than their counterparts with lesser number of elderly members/children in the households. 
Table 6 Household character-wise poverty and vulnerability. Source: Household Income Expenditure Survey-2016, Own calculations

\begin{tabular}{llcc}
\hline & Food poor & HVNFP & $\begin{array}{l}\text { High-food } \\
\text { vulnerable }\end{array}$ \\
\hline $\begin{array}{l}\text { Household characteristics } \\
\text { HH has old people (more than 65 years old) }\end{array}$ & & & \\
$\quad$ HH has no old age people & 35.42 & 8.85 & 24.01 \\
HH has 1 old age people & 36.34 & 9.69 & 25.85 \\
HH has 2 or more old age people & 37.11 & 12.72 & 29.63 \\
HH has children (less than 5 years old) & & & \\
HH has no children less than 5 & 29.46 & 6.74 & 16.71 \\
HH has 1 children less than 5 & 43.15 & 12.33 & 33.87 \\
HH has 2 children less than 5 & 53.24 & 13.97 & 46.65 \\
HH has 3 or more children less than 5 & 58.48 & 13.72 & 51.64 \\
\hline
\end{tabular}

\section{Conclusion}

Despite of progresses of Bangladesh in the context of poverty reduction, as reflected in HIES 2016 there are still 38.4 million people below the upper poverty line. With high informality in employment in one hand and regular environmental shocks on the other, there is argued to be substantial degree of economic vulnerability among households belonging to lower end of income distribution (Chaudhury 2003). Against this backdrop, more than 2 months of general holiday by the government of Bangladesh for containing COVID-19 has left millions of workers losing their jobs and/or income. Given the dominance of food consumption of the low income households of Bangladesh, due to this income shock, it is highly plausible that, a sizable proportion of households will not be able to meet minimum level of food consumption. Our analysis of food poverty, food consumption inequality and vulnerability with the recent nationally representative household survey of Bangladesh shows the importance of household demographic factors as well as environmental features of the area of residence playing the dominant role in food poverty and vulnerability. With as high as $35.49 \%$ food poor households on an average, having greater number of young children and/or having elderly members in the household substantially increases the incidence of food poverty. On the other hand, households with educated heads and/or, households with heads being an employer instead of daily labourer or self-employed, have lower incidence of food poverty. Our analysis has revealed the importance of area of residence in explaining food poverty and households living in environmentally vulnerable areas have higher incidence of food poverty.

The analysis has also shown significant differences in the incidence of food poverty between rural and urban areas with the former having as high as $38.25 \%$ food poor households. Our Gini index and Lorenz curve of inequality in food consumption across different consumption groups however shows little distributional differences between rural and urban households. A further disaggregation through Oaxaca-Blinder decomposition however reflects that there is sizeable and significant difference in food consumption among rural and urban households and the differences in endowments among these two groups account for almost half of this gap in food consumption expenditure.

Against the backdrop of COVID-19, with millions of workers losing their employment at least in the short term, in addition to food poverty, it is rather interesting to look at food vulnerability among different groups of households. Our food vulnerability index 
reflects that, in addition to the food poor households, COVID-19 like economic shock can bring another $9.03 \%$ non-food poor households below the food poverty line- thus as high as $44.52 \%$ households can be termed as food vulnerable who are highly likely to be unable to meet the minimum food requirement after such type of shock. In addition, as high as $24.36 \%$ households are found to be highly food vulnerable- these households have high likelihood to fall into food poverty after such a shock. In terms of area of residence, although river erosion prone area is found to host the highest proportion of food poor $(48.20 \%)$, it is the households of drought prone area who are found to have the highest percentages of highly vulnerable food poor (42.39\%) as well as the highest percentage of food vulnerable households (50.85\%). In addition to environmental factors, economic connectivity as well as job opportunities play important roles in explaining food vulnerability across the country. As for the demographic features of households, if households have greater number of elderly people and/or greater number of children in household then they tend to have greater likelihood to experience food poverty after COVID-19 like shock even if they were non-food poor before the shock. Given the importance of nutritional requirement of young children for early childhood development and of elderly for combating illness, food poverty of households with children/elderly can have long term consequences and thus needs to be considered with due importance.

Against the backdrop of COVID-19 pandemic, understanding food poverty and vulnerability is of particular importance for getting better insights of food consumption deficiency across different households. The study can therefore help in identifying and targeting different categories of food vulnerable households (e.g. chronically food poor, non-poor food vulnerable, highly food vulnerable) for government's social safety net programs and COVID-19 incentive packages. Based on the differences of household and community level characteristics, poverty reduction strategies can be effectively re-designed to incorporate the new poor in particular. In addition to effective digitalization of safety net programs, self-claim system, local and sector based listing can be useful for identifying the food vulnerable households especially during the time of COVID-19. As Devranjan and Jack (2007) argue, a well-structured social safety net program which incorporates simple public insurance scheme can be helpful in reducing vulnerability. In the context of Bangladesh, basic public insurance scheme within NSSS (National Social Safety Net Strategy) and its quick implementation can be instrumental in combating COVID-19 induced poverty. In addition, research like ours can serve as a guideline for understanding the financial requirement of cash or in-kind transfer programs.

Acknowledgements The authors would like to thank two anonymous reviewers for their useful and valuable comments.

Funding This study is not funded by any individual or organizations but has been conducted out of own interest of the authors.

\section{Compliance with Ethical Standards}

Conflict of interest The authors declare that they have no conflict of interest.

\section{Appendix}

See Tables 7 and 8. 
Table 7 OLS Regression results of expected Natural log of capita food consumption expenditure. Source: Household Income Expenditure Survey-2016, Own calculation

\begin{tabular}{|c|c|}
\hline Variables & Coefficients \\
\hline Age of the HH head & $\begin{array}{l}0.00406 * * * \\
(0.000156)\end{array}$ \\
\hline Age of the $\mathrm{HH}$ head mean centered squared & $\begin{array}{l}-5.73 \mathrm{e}-05^{* * *} \\
(8.19 \mathrm{e}-06)\end{array}$ \\
\hline HH size & $\begin{array}{l}-0.0992^{* * * *} \\
(0.00134)\end{array}$ \\
\hline HH size mean centered squared & $\begin{array}{c}0.0104 * * * \\
(0.000401)\end{array}$ \\
\hline Total operating land & $\begin{array}{l}0.00290^{* * * *} \\
(0.000600)\end{array}$ \\
\hline Total operating land mean centered squared & $\begin{array}{l}-8.38 \mathrm{e}-06^{* * * *} \\
(2.08 \mathrm{e}-06)\end{array}$ \\
\hline Dependency ratio & $\begin{array}{c}-0.176 * * * \\
(0.00873)\end{array}$ \\
\hline Sex of the HH head & $\begin{array}{l}0.0459 * * * \\
(0.00661)\end{array}$ \\
\hline HH head under SSNP & $\begin{array}{l}-0.0259 * * * \\
(0.00304)\end{array}$ \\
\hline Condition of the $\mathrm{HH}$ head & $\begin{array}{l}0.0558 * * * \\
(0.00454)\end{array}$ \\
\hline Hygienic condition & $\begin{array}{l}0.0546^{* * * *} \\
(0.00558)\end{array}$ \\
\hline Electricity dummy & $\begin{array}{c}0.123^{* * *} \\
(0.00439)\end{array}$ \\
\hline HH Head uses mobile phone & $\begin{array}{l}0.0846^{* * *} \\
(0.00496)\end{array}$ \\
\hline Telephone dummy & $\begin{array}{l}0.0896^{* * *} \\
(0.0186)\end{array}$ \\
\hline Computer dummy & $\begin{array}{l}0.124 * * * \\
(0.0122)\end{array}$ \\
\hline Internet access dummy & $\begin{array}{l}0.113 * * * \\
(0.00784)\end{array}$ \\
\hline Other asset & $\begin{array}{l}0.0724 * * * \\
(0.00374)\end{array}$ \\
\hline Dummy shock & $\begin{array}{l}0.0155^{* * *} \\
(0.00521)\end{array}$ \\
\hline Education of HH head (preprimary) & $\begin{array}{l}0.0410^{* * *} \\
(0.00582)\end{array}$ \\
\hline Education of $\mathrm{HH}$ head (primary passed) & $\begin{array}{l}0.0636^{* * *} \\
(0.00522)\end{array}$ \\
\hline Education of HH head (lower secondary) & $\begin{array}{l}0.0990 * * * \\
(0.00614)\end{array}$ \\
\hline Education of HH head (SSC passed) & $\begin{array}{r}0.126^{* * *} \\
(0.00781)\end{array}$ \\
\hline Education of HH head (HSC passed) & $\begin{array}{c}0.155 * * * \\
(0.00966)\end{array}$ \\
\hline
\end{tabular}


Table 7 (continued)

\begin{tabular}{|c|c|}
\hline Variables & Coefficients \\
\hline Education of HH head (Tertiary level) & $\begin{array}{c}0.224 * * * \\
(0.00983)\end{array}$ \\
\hline \multicolumn{2}{|l|}{ Education of HH head (base category) } \\
\hline HH Head works in agricultural sector & $\begin{array}{l}-0.0243 * * * \\
(0.00541)\end{array}$ \\
\hline $\mathrm{HH}$ head works in non-agricultural Sector & $\begin{array}{l}-0.00260 \\
(0.00518)\end{array}$ \\
\hline Division Dummy-Barisal & $\begin{array}{l}-0.209 * * * \\
(0.00949)\end{array}$ \\
\hline Division Dummy-Chittagong & $\begin{array}{l}-0.0243^{* * *} \\
(0.00837)\end{array}$ \\
\hline Division Dummy-Dhaka & $\begin{array}{l}-0.0943 * * * \\
(0.00834)\end{array}$ \\
\hline Division Dummy-Khulna & $\begin{array}{l}0.347 * * * \\
(0.00868)\end{array}$ \\
\hline Division Dummy-Mymensingh & $\begin{array}{c}-0.242^{* * *} \\
(0.0102)\end{array}$ \\
\hline Division Dummy-Rajshahi & $\begin{array}{c}-0.353 * * * \\
(0.00895)\end{array}$ \\
\hline Division Dummy-Rangpur & $\begin{array}{c}-0.365^{* * *} \\
(0.00888)\end{array}$ \\
\hline \multicolumn{2}{|l|}{ Division Dummy-Sylhet (base category) } \\
\hline Constant & $\begin{array}{l}7.538^{* * * *} \\
(0.0135)\end{array}$ \\
\hline Observations & 45,487 \\
\hline$R^{2}$ & 0.315 \\
\hline
\end{tabular}

SE in parentheses

$* p<0.1, * * p<0.05, * * * p<0.01$ 
Table 8 Oaxaca blinder decomposition of rural-urban food expenditure gap (Detailed). Source: Household Income Expenditure Survey-2016, Own calculations

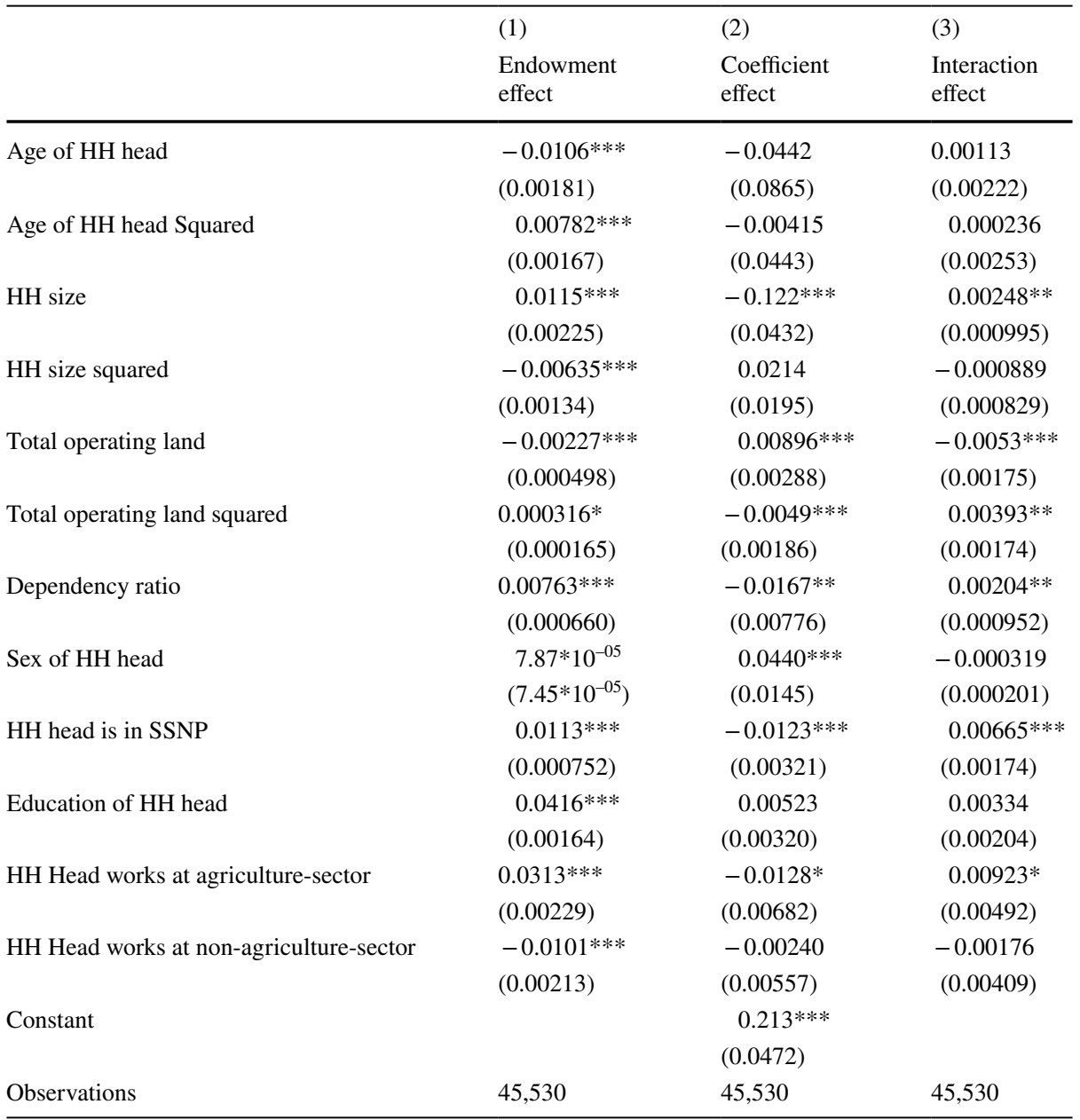

Robust SE in parentheses

$* p<0.1, * * p<0.05, * * * p<0.01$ 


\section{References}

Alamgir, M. (1974). Some analysis of distribution of income, consumption, saving and poverty in Bangladesh. The Bangladesh Development Studies, 2(4), 737-818.

Azam, M. S., \& Imai, K. S. (2009). Vulnerability and poverty in Bangladesh. Chronic poverty research Centre working paper, pp. 141

Azam, M. S., \& Imai, K. S. (2012). Measuring households' vulnerability to idiosyncratic and covariate shocks-The case of Bangladesh. Research Institute for Economics and Business Administration, Kobe University, Japan (Discussion Paper Series).

Bangladesh Bureau of Statistics (BBS). (2019). Final Report on Household Income and Expenditure Survey, 2016

Bidisha, S. H., Khan, A., Imran, K., Khondker, B. H., \& Suhrawardy, G. M. (2017). Role of credit in food security and dietary diversity in Bangladesh. Economic Analysis and Policy, 53, 33-45.

Blinder, A. S. (1973). Wage discrimination: reduced form and structural estimates. Journal of Human resources, 8(4), 436-455.

Borkotoky, K., \& Unisa, S. (2018). Inequality in food expenditure in India and the contributing factors. Journal of Quantitative Economics, 16(3), 647-680.

Calvo, C. \& Dercon, S. (2005). Measuring individual vulnerability. University of Oxford, Department of Economics, Economics Series Working Papers.

Chaudhuri, S. (2003). Assessing vulnerability to poverty: concepts, empirical methods and illustrative examples. Columbia University, New York: Department of Economics.

Chaudhuri, S., Christiaensen. L. (2002). Assessing household vulnerability to poverty: Illustrative examples and methodological issues. Presentation at the IFPRI-World Bank Conference on Risk and Vulnerability: Estimation and Policy Applications. September 23-24, Washington, D.C.

Chaudhuri, S., Jalan, J., \& Suryahadi, A. (2002). Assessing household vulnerability to poverty from crosssectional data: A methodology and estimates from Indonesia. Columbia University Libraries. https:// doi.org/10.7916/D85149GF.

Christiaensen, L., \& Subbarao, K. (2001). Towards an understanding of vulnerability in rural Kenya. Washington, D.C Photocopy: World Bank,.

Crawford, E., \& Thorbecke, E. (1980). The analysis of food poverty: An illustration from Kenya. The Pakistan Development Review, 19(4), 311-335.

Daymont, T. N., \& Andrisani, P. J. (1984). Job preferences, college major, and the gender gap in earnings. Journal of Human Resources, 19(3), 408-428.

Devarajan, S., \& Jack, W. (2007). Protecting the Vulnerable: The tradeoff between risk reduction and public insurance. The World Bank Economic Review, 21(1), 73-91.

Eigbiremolen, G. O., \& Ogbuabor, J. E. (2018). Measurement and determinants of food poverty: A dynamic analysis of Nigeria's first panel survey data. African Development Review, 30(4), 423-433.

Elbers, C., \& Gunning, J. W. (2003). Vulnerability in a stochastic dynamic model. SSRN Electronic Journal. https://doi.org/10.2139/ssrn.446405.

Faridi, R., \& Wadood, S. N. (2010). An econometric assessment of household food security in Bangladesh. The Bangladesh Development Studies, 33(3), 97-111.

Foster, J., Greer, J., \& Thorbecke, E. (1984). A class of decomposable poverty measures. Econometric Journal of the Econometric Society, 52(3), 761-766.

Fujii, T. (2016). Concepts and measurement of vulnerability to poverty and other issues: a review of literature. The Asian 'Poverty Miracle's (pp. 53-83). Northampton: Edward Elgar Publishing.

Greer, J., \& Thorbecke, E. (1986). Food poverty profile applied to Kenyan smallholders. Economic Development and Cultural Change, 35(1), 115-141.

Greer, J., \& Thorbecke, E. (1986). Food poverty profile applied to Kenyan smallholders. Economic Development and Cultural Change, 35(1), 115-141.

Hamadani, J. D., Hasan, M. I., Baldi, A. J., Hossain, S. J., Shiraji, S., Bhuiyan, M. S. A., \& GranthamMcGregor, S. (2020). Immediate impact of stay-at-home orders to control COVID-19 transmission on socioeconomic conditions, food insecurity, mental health, and intimate partner violence in Bangladeshi women and their families: an interrupted time series. The Lancet Global Health, 8(11), e1380-e1389.

Hoddinott, J., \& Quisumbing, M. A. R. (2003). Data sources for microeconometric risk and vulnerability assessments. Social Protection: World Bank.

Jones, F. L., \& Kelley, J. (1984). Decomposing differences between groups: A cautionary note on measuring discrimination. Sociological Methods and Research, 12(3), 323-343.

Khan, M. F. A., \& Islam, M. S. (2013). Vulnerability to climate induced drought: Scenario and impacts. CDMP, pp. 80 
Khandker, S. R. (2012). Seasonality of income and poverty in Bangladesh. Journal of Development Economics, 97(2), 244-256.

Kyereme, S. S., \& Thorbecke, E. (1987). Food poverty profile and decomposition applied to Ghana. World Development, 15(9), 1189-1199.

Kyereme, S. S., \& Thorbecke, E. (1991). Factors affecting food poverty in Ghana. The Journal of Development Studies, 28(1), 39-52.

Ligon, E., \& Schechter, L. (2003). Measuring vulnerability. The Economic Journal, 113(486), C95-C102.

Mottaleb, K. A., Mainuddin, M., \& Sonobe, T. (2020). COVID-19 induced economic loss and ensuring food security for vulnerable groups: Policy implications from Bangladesh. PLoS ONE, 15(10), e0240709.

Nyariki, D. M., \& Wiggins, S. (1997). Household food insecurity in sub-Saharan Africa: lessons from Kenya. British Food Journal. https://doi.org/10.1108/00070709710179363.

Oaxaca, R. (1973). Male-female wage differentials in urban labor markets. International Economic Review, 14(3), 693-709.

Olayide, O. E., \& Alabi, T. (2018). Between rainfall and food poverty: Assessing vulnerability to climate change in an agricultural economy. Journal of Cleaner Production, 198, 1-10.

Oni, O. A., \& Fashogbon, A. E. (2013). Food poverty and livelihoods issues in rural Nigeria. African Journal of Agricultural and Resource Economics, 8(311-2016-5562), 108-135.

Osmani, S. R., \& Ahmed, M. (2013). Vulnerability to Shocks and Coping Strategies in Rural Bangladesh. Institute of Microfinance.

Ozughalu, U. M. (2016). Relationship between household food poverty and vulnerability to food poverty: Evidence from Nigeria. Social Indicators Research, 125(2), 567-587.

Ozughalu, U. M., \& Ogwumike, F. O. (2013). Vulnerability to food poverty in Nigeria. African Development Review, 25(3), 243-255.

Rabbani, A. (2014). Household food security in Bangladesh: going beyond poverty measures. The Bangladesh Development Studies, 37(1 \& 2), 103-125.

Rahman, H. Z., Das, N., Matin, I., Wazed, M. A., Ahmed, S. \& Jahan, N., Umama, Z. (2020) Livelihood, Coping and Support during COVID19 crisis. PPRC-BIGD, April, 2020.

Ravallion, M., \& Sen, B. (1996). When method matters: Monitoring poverty in Bangladesh. Economic development and cultural change, 44(4), 761-792.

Sumner, A., Hoy, C., \& Ortiz-Juarez, E. (2020). Estimates of the Impact of COVID-19 on Global Poverty. UNU-WIDER, April, 800-9.

Suryahadi, A., \& Sumarto, S. (2003). Poverty and vulnerability in Indonesia before and after the economic crisis. Asian Economic Journal, 17. 45-64.

Townsend, R. M. (1994). Risk and insurance in village India. Econometrica Journal of the Econometric Society, 62(3), 539-591.

Udry, C. (1995). Risk and saving in Northern Nigeria. The American Economic Review, 85(5), 1287-1300.

Winsborough, H., \& Dickinson, P. (1971). Components of negro-white income differences. Age, 25(34), $35-44$.

Zereyesus, Y. A., Embaye, W. T., Tsiboe, F., \& Amanor-Boadu, V. (2017). Implications of non-farm work to vulnerability to food poverty-recent evidence from Northern Ghana. World Development, 91, 113-124.

Publisher's Note Springer Nature remains neutral with regard to jurisdictional claims in published maps and institutional affiliations. 